Language Learning, Recasts, and Interaction Involving AAC:

Background and Potential for Intervention

\author{
Michael T. Clarke \\ University College London \\ Gloria Soto \\ San Francisco State University \\ Keith Nelson \\ Penn State University
}

\begin{abstract}
Author Note
Michael Clarke, Research Department of Language and Cognition, University College London, London (UK); Gloria Soto, Department of Special Education and Communication

Disorders, San Francisco State University; Keith Nelson, Department of Psychology, Pennsylvania State University.

Correspondence concerning this paper should be addressed to Michael Clarke, Research Department of Language and Cognition, Chandler House, 2 Wakefield Street, University College London, London (UK). Email: m.clarke@ucl.ac.uk
\end{abstract}




\begin{abstract}
For children with typical development, language is learned through everyday discursive interaction. Adults mediate child participation in such interactions through the deployment of a range of co-constructive strategies, including repeating, questioning, prompting, expanding, and reformulating the child's utterances. Adult reformulations of child utterances, also known as recasts, have also been shown to relate to the acquisition of linguistic structures in children with language and learning disabilities and children and adults learning a foreign language. In this paper we discuss the theoretical basis and empirical evidence for the use of different types of recasts as a major language learning catalyst, and what may account for their facilitative effects. We consider the occurrence of different types of recasts in AAC-mediated interactions and their potential for language facilitation, within the typical operational and linguistic constraints of such interactions. We also consider the benefit of explicit and corrective forms of recasts for language facilitation in conversations with children who use AAC. We conclude by outlining future research directions.
\end{abstract}

Keywords: Recast; Augmentative and alternative communication; Children; Language; Intervention 
Language Learning, Recasts, and Interaction Involving AAC:

Background and Potential for Intervention

Despite being able to communicate more functionally through the support of augmentative and alternative communication (AAC) tools and strategies, many children who use AAC still experience persistent difficulties in their acquisition of language, in particular in relation to their expressive vocabulary and production of grammatically complete utterances (Binger \& Light, 2008; Smith 2015). A range of factors related to individual differences, including differences in communicative environments and AAC systems, interact to account for limited language use. From a perspective that views everyday conversational experiences as the engine room of child language learning (e.g., Clark, 2014), careful attention to the features of children's interpersonal interactions is warranted.

Synergies between child and adult language use in interaction are considered central to theories of language acquisition (e.g., Clark, 2014). In conversational interaction, each participant's contribution makes relevant a particular class of next turn by the next speaker. For example, a turn that provides an evaluation (e.g., Child: Yummy cake) makes relevant an agreement or disagreement next (e.g., Adult: Yes, it's an amazing birthday cake). As such, conversations develop dialectically as participants design their turns in response to their coparticipants' preceding contribution. The moment-by-moment practices of conversational interaction seem important for child language learning, where reciprocal relationships emerge between children's underlying language abilities, their use of language, and adult's contributions, including scaffolding of children's output (e.g., reformulations of child utterances).

In the course of conversation, the adult typically attunes to the child's ability and uses a range of pragmatic strategies to scaffold child language use. For example, such turns may serve 
to clarify the child's intended meaning, introduce new linguistic forms and functions or provide information about word meaning and use (Clark, 2014; Morgenstern, Leroy-Collombel, \& Caët, 2013). Where children produce errors in their language production, adult responses may function as implicitly or explicitly corrective, such as in the use of reformulations of the child's incomplete or ungrammatical utterance (e.g., Chouinard \& Clark, 2001; Morgenstern et al., 2013). Where children's utterances are well constructed and delivered, adult response-types may be non-corrective as in repetitions or expansions of the child utterance to encourage the production of new, more complex linguistic units (Clark, 2014). The presence of these corrective and non-corrective adult pragmatic strategies has been observed across languages such as Turkish (Kuntay \& Slobin, 2002), French (Clark \& de Marneffe, 2012), Tzeltal (Brown, 2000), and others.

Adult scaffolding appears to serve two primary purposes: (a) to sustain the child's conversational participation (with a minimum of utterance generation or planning); and (b) to create a linguistic environment that supports the acquisition and production of linguistic structures through exposure to, storage, and retrieval, of new and more complex language forms. In theory, this allows the child to derive new generalizable language knowledge through processes such as structural comparison and rule induction (e.g., Nelson, 2000). A type of adult reply that appears to facilitate the acquisition of new words and grammatical structures is the recasting (i.e., reformulation) of child utterances (e.g., Nelson, 1977; Clark, 2014). The use of recasts has been extensively documented in research on first language development (L1), language learning by children with communication difficulties, and in second language acquisition (L2) in the context of adult-adult and adult-child interaction, with over 60 studies in the last two decades examining their use (e.g., Nicholas, Lightbown, \& Spada, 2001; Mackey \& 
Goo, 2007; Nelson, 2000). The reasons why the use of recasts engenders such interest seems primarily related to their universality (occurring across languages, and across language learning contexts), their frequency of occurrence and apparent effectiveness. While the design of recasts can vary considerably, their use is regarded as a major language learning facilitator in interaction as demonstrated in both experimental and naturalistic correlational designs (e.g., Camarata, Nelson, \& Camarata, 1994; Clark, 2014; Saxton, 2005). Recasts have also featured as an important technique in intervention programs for children with language and learning disabilities (e.g., Camarata et al., 1994; Nelson, Camarata, \& Camarata 1996). However, despite their apparent relevance to language acquisition, the study of adult language scaffolding and recasts in the AAC field is significantly limited (e.g., Soto \& Clarke, in press). In this paper we discuss the theoretical basis and empirical evidence for recasts as a major language learning catalyst, focusing particularly on recasts deemed to be explicitly or implicitly corrective. We then consider their occurrence in interactions involving AAC, and their implications for language learning in an AAC context. We finish by outlining future research directions.

\section{What is a Recast?}

The use of recasting has been studied in several fields such as L1 acquisition, and L2 learning, and in relation to children with communication disorders (e.g., Ellis \& Sheen, 2006; Farrar, 1990; Nelson, 1977; Saxton, 2005). While each field may use the term recast with slightly different meaning, the universally reported features of recasts are that (a) they immediately follow the child's or language learner's utterance; (b) they incorporate elements of the child's or language learner's utterance; and (c) they provide an enhanced and/or contrasting version of that utterance by changing one or more sentence components, while maintaining reference to its basic meaning (e.g., Baker \& Nelson, 1984). As Bohannon and colleagues 
describe, the adult generates a recast when he or she "...expands, deletes, permutes, or otherwise changes the [child's utterance] while maintaining significant overlap in meaning" (Bohannon, Padgett, Nelson, \& Mark, 1996, p. 551). Sometimes, recasts provide a corrective contrast with the child's immediately prior turn through the provision of an enhanced version of the child's illformed utterance, as in the example below reproduced from Saxton (2005, p.24).

\section{Child: It might get loosed down the plughole}

Adult: Lost down the plughole?

Equally, some recasts give no clear-cut correction but still offer potential for facilitation of acquisition by providing a structural contrast with an errorless sentence produced by the child as in the following constructed extract, which illustrates an adult expanding the child's utterance into one that is more complex:

Child: That's a big horse.

Adult: Yep, that's a big horse with lots of black spots.

Sometimes, recasts may introduce multiple changes, as in the following example, whereby the adult both expands on and corrects components of the child's utterance:

Child: Why does he that?

Adult: Mmm, I am not sure why he does that.

Despite an extensive body of literature, the reasons why recasts contribute to language development and the specific features of recasts that make them beneficial to language learning continue to attract considerable debate in the L1 and L2 fields (e.g., Al-Surmi, 2012; Goo \& Mackey, 2013; Saxton, 2005). There are several theories explaining the facilitative power of recasts. One such theory is the Contrast Theory of Corrective Input (Saxton, 1997; Chouinard \& Clark, 2003). According to this theory, two specific features of recasts may explain their 
potential to facilitate language development: (a) they are models that are contingent on a child's error, and signal that the child did not produce the right form for the meaning intended; and (b) the presentation of those models happens in the context of conversational interaction. It is in the context of such conversations that adults use recasts as a type of correction to alert the child to the error and propose an alternative form. Children might learn to interpret adult recasts as corrective feedback, because parents recast ungrammatical utterances more often than grammatical ones (e.g., Chouinard \& Clark, 2003). Saxton (2005) added a Direct Contrast Hypothesis, which predicts that the facilitative power of recasts rests on the immediate juxtaposition of an adult correct model to a child's erroneous, or immature utterance. This immediate juxtaposition provides children with an opportunity to compare their own erroneous form with a more conventional version of their intended meaning (Clark, 2014).

Much earlier than the theories aforementioned, Nelson (e.g., 1977, 1987) had used the term cognitive comparison to explain a variety of ways in which children may notice and analyze contrasts between their own utterances and contingent utterances by the adult. Nelson and his colleagues have refined this theory through a number of experimental studies that demonstrate that children acquire new syntactic structures not only from corrective adult responses but also from adult recasts that provide contrast (are more complex than the child's) but are not corrective of any error (e.g., Bohannon et al., 1996; Camarata \& Nelson, 1992; Nelson, 1987; Nelson et al., 1996; Nelson \& Welsh, 1989).

L2 researchers use the term noticeability to explain the facilitative power of recasts (i.e., in order to be effective, recasts must be noticed by the language learner as expanding and/or correcting an erroneous linguistic form). While L1 researchers do not typically use the term noticeability, they do propose that the child attends to (notices) the adult reformulation. Evidence 
that children attend to the adult reformulation comes mainly from the child's (a) immediate reformulation of his or her turn prior turn incorporating parts or whole of the adult's utterance, (b) spontaneous use of forms presented as recasts but then used by the child at later points in a conversation, and/or (c) evidence of production or comprehension of syntactic or lexical forms days or weeks later in spontaneous conversation or on specific language measures (Baker \& Nelson, 1984; Camarata et al., 1994; Chouinard \& Clark, 2001). The role of child reformulation of their prior utterance in the form of full or partial repetition of the adult's recast is evident in children with typical language development (Clark, 2014; Chouinard \& Clark, 2001). Prior to the acquisition of fully generative linguistic structures, some children with typical development are observed first to produce language that includes both generative and repeated segments which are derived in whole or part from the prior utterance of the communicative partner (Scollon, 1976). Where the child generates an immediate and enhanced version of his or her own prior turn based on the content and/or form of the adult recast, a 3-turn sequence may be observed, such as in the following exchange:

\section{Child: I runned super fast.}

Adult: wow, you ran super fast?

Child: Yeah, I ran super fast.

In this example, the child's reformulation provides an opportunity for the practice of the target structure. The term repair is often used in the literature, as it is in this paper, to describe the child's modified utterance following a recast. We note also however that because many recasts signal some form of issue with the child's prior turn while also displaying an enhanced formulation of that turn, they can also be described as a class of repair themselves (other-initiated other repair; Schegloff, Jefferson, \& Sacks, 1977). 
Most recasts are not overtly treated by the child as corrective, as evidenced by immediate, next-turn repair of his or her prior utterance. Indeed, it has been estimated that only $20 \%$ of adult reformulations (in Clark's terms) precipitate children's repair of their prior turn (Clark, 2014). Limited repair by children has been attributed to the fact that they treat the majority of recasts as having a pragmatic function other than a corrective one, such as topic continuation or the seeking of clarification (Chouinard \& Clark, 2003). For example, in the previous "run-super-fast" example, it would seem perfectly relevant for the child to respond to the adult's recast with a simple affirmation as in:

Child: I runned super fast.

Adult: Wow, you ran super fast?

Child: Yeah!

Children's immediate repair is relatively infrequent and does not appear necessary for language acquisition where, for example, children's acquisition mechanisms are considered sufficiently powerful to ensure that recasts of many sorts (e.g., corrective and non-corrective) contribute to acquisition (e.g., see Nelson, 2000). Where repair is observed, it may not represent irrefutable evidence of language acquisition. Nevertheless, theoretically, the child's repair of his or her own prior utterance in response to a recast allows him or her to practice and automatize the retrieval of target language relevant to a conversational context. It also provides evidence for on-the-spot language processing, and potentially also for the child's encoding of newly identified structural information into long term memory. This language processing may lead to the child establishing new internal hypotheses about how language is constructed. 
If children are to notice the recast and make use of the adult's language model, they need to be able to compare what they said with the adult reformulation (e.g., Chouinard \& Clark, 2003; see also Ellis \& Sheen, 2006 in relation to L2 learning). Arguably, key elements of the noticeability or salience of recasts as corrective are (a) their positioning immediately after the child's turn, (b) their design features, and (c) the child's linguistic readiness (Nelson, 1987) to engage cognitively with the enhanced language model provided by the recast (and to repair the utterance immediately or at a later date).

Noticeability and sequential positioning of recasts. The sequential immediacy of the recast is thought to create the optimal conditions for the child to attend to the formal properties of his or her utterance in relation to the adult's utterance, without losing its original meaning (e.g. Saxton, 2005). For corrective recasts, the immediate juxtaposition of the child error and a correct adult version is thought to enhance the salience of the linguistic target, and minimize the cognitive load required to process the accuracy of his or her own language form. Saxton (2005), proposes that recasts facilitate a sustained flow of conversation because they (a) are contingent on the child's utterances; (b) are likely to reference topics of interest to the child; and (c) include lexical items from the child's original utterance, making their comprehension more likely (Saxton, 2005). Work in the field of L2 learning also proposes that the value of the positioning of recasts enhances their ability to provide negative evidence within "the context of a meaningful and sustained communicative interaction” (Lyster \& Saito, 2010, p. 278), without breaking the communicative flow (e.g., Goo \& Mackey, 2013).

Noticeability and the design of recasts. The extent to which recasts are noticed by children as corrective appears related to their design. Because recasts have been investigated extensively in the fields of L1, L2, and communication disorders, they have been classified 
according to different perspectives, including length (e.g., partial or expansion), mode (e.g., interrogative or declarative), number of changes (e.g., simple or complex), linguistic focus (e.g., morphology or syntax), and contrast (explicit or implicit).

A number of studies in the L2 literature have directly examined the relationship between the different types of recasts and their saliency (e.g., Lyster, 1998; Sheen, 2006). Saliency falls within a continuum from low to high, and is defined as the degree to which a language learner is able to notice a linguistic feature in the input. Sheen argues that the more explicit recasts are, the more salient they become and thus the more likely to be noticed. A key proposal is that for corrective recasts to function as noticeably corrective and facilitative of language learning, they need to be designed such that they signal that an error has been committed and draw attention to the linguistic target (Lyster, 1998). According to Sheen, a recast becomes explicit when it is corrective in nature, such as when it is declarative in form, is short, and involves substitution of the learner's erroneous form rather than deletions or additions. Manipulation of intonation, intraturn pauses, and prosodic emphasis may also mark a recast as corrective (e.g., Ammar \& Spada, 2006).

Noticeability and developmental readiness. In the context of L1 and adult-child L2 language learning, it is proposed also that the effectiveness of recasts as language facilitating phenomena is linked to a relationship between recast design (e.g., in terms of its level of challenge for the child), and the child's current linguistic acquisition level, that is his or her linguistic readiness (e.g., Nelson, 1987). To detect mismatches between his or her own utterance and the adult recast, the child is required to assess what was wrong or missing from his or her prior utterance. While individual child differences such as age, gender and motivation, are potentially influential on children's noticing of recasts as corrective, it is contended that, in an L2 
learning context, the interaction between a learner's developmental readiness for language learning, the language target, and recast design, is critical for noticing to occur (see Goo \& Mackey, 2013). Noticing a recast as corrective requires dual processing of both meaning and form, and places a significant load on the learner's attentional resources. In their meta-analysis of recast studies in an L2 context, Miller and Pan (2012) suggest that (a) language learners are more likely to notice recasts when these are developmentally appropriate, short, and similar to the learner's original utterance (e.g., see also Bohannon et al., 1996 for evidence in L1); and (b) learners who are less linguistically advanced are understood to need more explicit forms of recasts for noticing to take place (e.g., Oliver \& Mackey, 2003).

\section{Recasts as a Clinical Tool}

Strategic manipulation of recasts in conversation is a frequently used approach to language intervention for children with communication disorders (e.g., see Camarata \& Nelson, 2006). The approach is grounded on social-interactive theories where the main premise is that language is best learned by participating in conversational exchanges with appropriate adult models that follow the child's lead (i.e., interests and initiations), and respond contingently to the child's behavior (Abbeduto \& Boudreau, 2004; Kirchner, 1988). Such theories have led to the development of discourse-based intervention programs that incorporate adult scaffolding in the context of social interaction.

Recast interventions have been effective in increasing the expressive vocabulary and grammatical skills of children with a range of communication disorders including children with autism (e.g., Scherer \& Olswang, 1989), specific language impairment (e.g., Camarata \& Nelson, 1992; Nelson et al., 1996), language learning disabilities (Stiegler \& Hoffman, 2001), and language delay (Ruston \& Schwanenflugel, 2010). The use of recasts as a therapy technique is 
typically embedded within semi-structured conversations that target authentic use of the linguistic target(s) (Eisenberg, 2013). Compared with other approaches (e.g., imitation training), conversational recasts are understood to require fewer trials to achieve spontaneous production and greater generalization of linguistic targets (Camarata et al., 1994; Nelson et al., 1996).

As outlined above, recasts can be defined in a variety of ways and links between recast design and delivery and child language acquisition can be difficult to disentangle (e.g., see Saxton, 2005 for review). As an element of adult-child interaction, recasts are unlikely to stand alone as single critical ingredients of adult input. Rather, adult-child interaction operates with a dynamic system of resources. For instance, Nelson and colleagues have extensively studied the effects of recasting on a number of lexical and grammatical measures and conclude that the therapeutic value of recasting during intervention increases when accompanied by other important learning conditions. These conditions include high levels of child attention with mutual emotional engagement between adults and children, and the generation of a linguistically challenging environment where adults are responsive to children but place low demands for immediate response from children (e.g., Baker \& Nelson, 1984). Using recasts along with these learning conditions, developmental gains in syntax have been demonstrated for children with typical development (e.g., Nelson \& Welsh, 1998) and children with specific language impairment (Haley, Camarata, \& Nelson, 1994). Improvements in language levels have also been reported for children with autism spectrum disorder (Heimann, Nelson, Tjus, \& Gillberg, 1995; Tjus, Heimann, \& Nelson, 1998).

Despite the theoretical and clinical relevance of recasting, little is known about their use in interactions involving AAC. Children who rely on AAC are seen to engage in conversational interactions characterized by recurring patterns, whereby their contributions are explicitly co- 
constructed. The occurrence and type of recasts seen in such conversations and, critically, the extent to which these children may also benefit from recasts is poorly understood.

\section{The AAC Context}

\section{Characteristics of Interaction Involving use of AAC}

While, by default, all conversation is co-constructed by its participants, in the AAC field, co-construction has been used to characterize the collaborative efforts of people who rely on $\mathrm{AAC}$ and their communication partners in building contributions of the person who uses AAC, which typically emerge incrementally over a series of turn exchanges (e.g., Solomon-Rice \& Soto, 2011). In interaction involving AAC, co-construction overwhelmingly operates through adults' use of interrogatives, and expansions of children's contributions (Binger \& Light, 2008; Sutton, Soto, \& Blockberger, 2002). Typically, children's single concept contributions form the basis of the adults' exploration and clarification of intended meaning, particularly for children who use graphic symbols where the selected symbol may have an indirect relationship with the proposed intention. Children who rely on AAC participate in these interactions primarily via the provision of confirmation or denial/rejection of adults' candidate interpretations. This pattern of interaction is one aspect of the broader feature of asymmetry in these types of interactions (e.g., Clarke \& Wilkinson, 2007; Solomon-Rice \& Soto, 2011).

Given the apparently important role that processes of conversational interaction have in facilitating language learning, concerns exist that the seemingly entrenched and relatively restricted patterns of interaction overwhelmingly observed in these children's conversations may reduce language learning opportunities, including the practice of the grammaticalization of utterances in authentic conversations, with important implications for their grammatical development (Binger \& Light, 2008; Sutton et al., 2002). 


\section{Recasts in Interaction Involving AAC}

Adult or peer reformulations of child utterances are a recurrent feature of co-construction practices in interaction involving AAC (e.g., Solomon-Rice \& Soto, 2011). Yet evidence from the AAC literature concerned with inter-personal interaction suggests that they are normally treated by the child as serving functions other than corrective (e.g., Clarke, 2016) (e.g., request for clarification; voicing the child's intentions etc.). In the extracts below, we present a first inventory of recast forms commonly observed in AAC-mediated interaction and their possible functions. The excerpts are from video recordings of conversation-based intervention sessions that were part of a larger study examining the impact of adult scaffolding on the expressive vocabulary and grammatical skills of children who rely on AAC. The participants were eight children (three girls and five boys), aged 8-14, with a range of developmental disabilities, who relied on AAC to communicate (see Soto \& Clarke, in press). The examination of extracts presented here is a qualitative sequential analysis that draws on the principles and practices of conversation analysis (e.g., Richards \& Seedhouse, 2016).

In question-answer exchanges, which are overwhelmingly common in these conversations, adult questions following child contributions are structurally designed as recasts; specifically recasts in which the child's contribution is reformulated in an interrogative form. For example, Extract 1 illustrates the adult use of an interrogative recast (Line 04) and the child's treatment of it as a request for clarification. The extract is taken from a conversation-based intervention session between a teacher $(\mathrm{T})$ and a child $(\mathrm{C})$, aged 9, who used a speech-generating device (SGD). In addition to $A A C$ journal transcription practice, the following notations are used: (a) double brackets to describe non-verbal actions such as ((nods)), (b) double underlining to 
indicate increased stress and volume in naturally spoken utterances, and (c) horizontal arrows $(\rightarrow)$ to highlight lines of particular focus in the extract.

\section{Insert Extract 1 About Here}

In response to the child's contribution "I to go my house cousin Alex Aby" (Line 02) the teacher provides immediate acknowledgement and explicit feedback on her apparent understanding of the turn saying, Ok that's a little confusing (Line 03). The teacher then immediately appears to offer a candidate treatment of the child's turn -- So were you at your house?-- and quickly re-works this to provide a recast, You went to your cousin house and your cousins are Alex and Aby? (Line 04), designed as an interrogative, as indicated by rising intonation (shown by the use of question mark). Here the child treats the adult's turn as a form of request for clarification providing a confirmation by nodding (Line 05), possibly in relation to the adult's claim that the child's turn was confusing and the provision of a candidate: So you were at your house.

The second extract, showing an example of explicit co-construction of the child's contribution, is taken from a conversation between a child (M) aged 13 and his teacher (T). Here M says "Boy" (Line 01) using his SGD, to which T asks, Boy what? (Line 02) and M replies, “Reading a book” (Line 03). Next T combines M's turns delivered pre- and post-question (Lines 01 and 03), to voice her hearing of M's contribution thus far. She produces this recast with interrogative prosody, saying, Boy read a book? (Line 04). Like Extract 1, the child using AAC (M) treats T's turn as a form of request for clarification and provides a confirmation by nodding his head. 
Pragmatically, and like other naturally speaking language learners, children who rely on AAC typically treat recasts not as corrective or making relevant some form of re-working of their prior turn as evidenced by a wealth of AAC interaction research (e.g. Clarke, 2016). Recasts (overwhelmingly interrogative) seen in these children's conversations may provide language facilitation for children with acquisition capabilities sufficient to extrapolate and internalize language rules from such turns, without a need for children to repair their prior erroneous or immature turn. Indeed, it is very possible that many children who rely on AAC develop language competence in spite of the restrictive patterns of interaction in which they engage. However, we argue that in an AAC context, language output involving use of AAC systems takes on enhanced importance in processes of language acquisition. In addition to theorized benefits of child immediate repair following adult recasts discussed above (e.g., to rehearse the retrieval of language), children who use AAC must learn to manage the linguistic and operational demands of their AAC system, that is the integration of spoken language learning input with output produced via AAC. Indeed, it is possible that for children who use AAC, the frequency of use of certain constructions (e.g., I was), has an impact on the mental representation of such constructions evidenced by its generalized use (i.e., conventionalized) across topics, partners and contexts (e.g., Bybee, 2006). In addition, immediate repair also allows for in-context support for learning operational aspects of AAC use. Evidence for the benefit of output is seen in research suggesting that both input and production are more facilitative for vocabulary acquisition by young children who use AAC than input alone (e.g., Romski et al., 2010). In Romski and colleagues' study with children beginning to use AAC devices, children made higher vocabulary gains when they were expected and prompted to use their AAC systems than when they received augmented input alone. In the absence of robust 
evidence, immediate repair of prior utterances by children relying on AAC has the potential to shed light on relationships between recast design and child noticing.

For example, in the context of language intervention (Soto \& Clarke in press), adult recasts that mark the targeted element(s) for correction with forms of emphasis, have been seen to evoke immediate repair by the child. Extract 3 is taken from an exchange between a teacher (T) and child (J). $\mathrm{J}$ is 12 years old and uses a SGD. This exchange is characterized by the teacher's expansion of the child's utterance "Children" (Line 02), with the declarative recast: $\underline{\underline{T h e}}$ children (Line 03). The inclusion of the determiner $\underline{\underline{T h e}}$ is produced with marked stress compared to the rest of adult utterance and surrounding talk. In this instance the child treats the adult turn as a corrective recast as evidenced by her immediate re-doing of her prior utterance, this time saying "The children" (Line 04).

\section{Insert Extract 3 About Here}

The possibility of evoking immediate child re-working of their prior turn through the design of an explicit recast that emphasizes contrast between the child and adult versions is illustrated in Extract 4. In this instance, taken from a conversation between a teacher $(\mathrm{T})$ and child (C) aged 9, the adult generates what might be described as a multi-move (Sheen, 2006) recast. C spells " $c-a-m-p$ " using her SGD, followed by production of the single word "Rock" (Line 02). Once the central meaning of C's turn is established, the teacher produces the recast, Camp rock is movie or is a movie, is $\underline{\underline{a}}$ movie? (Line 05). In this instance, the teacher repeats C's turn verbatim, then apparently offers an alternative production emphasizing the missing determiner $\underline{\underline{a}}$. As such, the teacher's turn seems designed to maximize C's noticing of the contrast between her own turn "Is movie" and the enhanced version provided by the teacher: Is $\underline{\underline{a}}$ movie. The contrast is emphasized, it seems, by the teacher's repetition of Is a movie. Arguably, 
the production of the recast as an interrogative that offers alternative versions of the prior turn (the child's own utterance or the adult's version), places constraints on what C might relevantly do next. $\mathrm{C}$ treats the teacher's turn as a corrective recast providing a next turn that incorporates the determiner $\underline{\underline{a}}$ albeit without the original auxiliary "is."

\section{Insert Extract 4 About Here}

The next three extracts illustrate instances where the child spontaneously treats the adult recast as corrective as evidenced by the immediate repair of her prior utterance. In Extract 5, the teacher $(\mathrm{T})$ provides an interrogative recast plus a meta-interactional comment on it. Immediately next, N repairs his initial utterance saying, "I want to go playground" (Line 03).

\section{Insert Extract 5 About Here}

In Extract 6, $\mathrm{T}$ and $\mathrm{C}$ were looking at a picture of $\mathrm{C}$ and $\mathrm{T}$ asks: How old were you here? (Line 01). As a question it makes relevant an answer next from $\mathrm{C}$ and an answer that might be produced minimally but perfectly relevantly with a single word numeral.

\section{Insert Extract 6 About Here}

$\mathrm{T}$ immediately follows the question with a declarative recast given some emphasis by increased stress and volume: You were 6 years old so that was $\underline{\underline{3} \text { years ago. }}$. Noticeably, without further prompting, $\mathrm{C}$ re-works her own turn to provide an enhanced production based on the adult recast, saying, "6 years old." In this instance the teacher's recast appears to precipitate active language work by $\mathrm{C}$ on the form of her utterance with the addition of "years old.".

The final two extracts illustrate examples of recasts that are offset from the child's original turn. In Extract 7 we propose that the adult turn at Line 04 is classifiable as a recast in relation to the child turn at Line 01 . However, rather than immediately following the child's turn, the recast is postponed until after some work on the potential meaning of the child's turn has 
been undertaken. This conversation is between a teacher $(\mathrm{T})$ and a child $(\mathrm{N})$ who is aged 13 and who also uses a graphic symbol-based SGD. At the point at which this extract is taken, $\mathrm{N}$ and $\mathrm{T}$ had been talking about a recent trip to the snow with his family.

\section{Insert Extract 7 About Here}

The extract begins with N saying, "Sled" (Line 01). The teacher then seeks clarification as to whether this refers to an activity that took place with the question: Is that something you did? (Line 02) making relevant a simple yes/no response and the minimally relevant next turn, and $\mathrm{N}$ confirms this with a nod (Line 03). The teacher then says, You went on a sled (Line 07). While not coming directly after N's production of "Sled" this teacher's turn is designed as a declarative recast in relation to "Sled", that is, "Sled" (Line 04) forms the platform for the exchange. Inserted between the platform turn (Line 01) and the recast (Line 04) is a questionanswer sequence (Lines 02 and 03) accomplishing a better understanding of the intended meaning of the single word "sled."

Extract 8 provides a further example of a similar class of exchange. Here the adult recast is offset from the child's platform turn by a brief two-turn exchange. This brief exchange seems broadly concerned with the adult providing a receipt of the SGD generated contribution (Line 02), and the child confirming the adult receipt with a nod (Line 03). In this instance $\mathrm{T}$ and $\mathrm{M}$ (also seen in Extract 2) are looking at pictures on an $\mathrm{iPad}^{(}{ }^{1}$. Subsequently, the teacher generates an interrogative recast: The boy is waving? (Line 04), designed as an expansion of M's single word contribution “Boy” (Line 01). M confirms T's expansion as an accurate candidate expansion of his turn, generating "Yeah" (Line 04).

Insert Extract 8 About Here 
The extracts presented here have illustrated ways in which adult turns that are classifiable as recasts occur in interactions involving AAC and how they may be treated as corrective or otherwise by children. It would seem from these extracts and from the review and discussions above that recasts have strong potential for supporting language learning through language use in interaction for children relying on AAC. Compelling evidence for their impact in interactions involving AAC, however, is limited to date (e.g., Soto \& Clarke in press) and stronger claims will await convergent findings from multiple research projects.

\section{Discussion}

Drawing on literature from first language acquisition, second language learning, and communication disabilities research, this paper has outlined the theoretical and empirical case for recasts as an important element of adult scaffolding of child language development. Recasts provide children with extensive feedback about how language is assembled and deployed, which may lead them to repair or expand a just produced turn, and/or adopt new language rules.

Partner reformulation, or voicing, of utterances appears to be a recurrent feature of conversations involving children's use of AAC (e.g., Clarke, 2016; Solomon-Rice \& Soto, 2011). In the adult-child interactions studied in this paper, many adult reformulations are designed as recasts. While recasts are deemed to occur immediately following the child's turn, we have suggested that, as part of the common practices of co-construction seen in these children's conversations, adult turns classifiable as recasts may be offset from the child's turn to which they refer (Extracts 7 and 8). We have also observed that recasts may bring about immediate repair by the child. Child repair by itself is not evidence of acquisition. Acquisition has only occurred after the linguistic target has been internalized and the child has reached a level of automaticity in its use (e.g., Miller \& Pan, 2012). However, for children who use AAC, 
learning and using language requires the integration of spoken language input with the symbolic representation of language on their AAC system (e.g., graphic symbols), and its organizational architecture, and the development of effective motor plans to automatize the retrieval of language from the device. Children who rely on AAC are then also challenged to deploy language in the high-speed bustle of face-to-face conversation. If language is a resource for and a product of interpersonal interaction, then, arguably, for children who rely on AAC the immediate repair of language generated via AAC in response to feedback may be critical for long-term language mastery; perhaps far more so than is the case for naturally speaking children. In addition, child AAC-mediated repair of a prior utterance allows for timely adult support of AACrelated child learning. However, more refined research is needed to determine how adult feedback can best be designed and delivered to maximize child language learning, without interrupting the flow of the conversation and de-motivating children for whom AAC use may be effortful. Equally, the role of child repair in facilitating language learning for children who use AAC requires careful examination.

\section{Future Research Directions}

In designing research to help clarify when sequences of conversational interaction directly contribute to child progress toward more language skills, it is valuable to consider intervention work with children with language delay who do not rely on AAC (see Nelson, 2000). In such work, within the conversational experience of each child, it has been possible to contrast control acquisition targets that are withheld for a period, other acquisition targets that receive recasting, and still other acquisition targets that receive modeling and prompts for the child to imitate the adult model. By extending this approach to children who rely on AAC whose current levels of expressive language skills are known, multiple language acquisition targets 
could be chosen, with some given specific procedural treatments and others used as controls. It would then be feasible to collect evidence on when a child achieves spontaneous use of language target mastery in relation to planned procedural variations/contrasts. Using this kind of design, it would be informative, for example, to examine the extent to which long-term acquisition is enabled by immediate repairs as opposed to non-repair spontaneous conversational extensions, that is the degree to which spoken recasts are more or less facilitative than spoken recasts plus prompt for repair. Given the need for children who rely on AAC to manage the incongruity of hearing spoken language, producing language via graphic symbol representations, and learning the operational demands of the AAC system, one useful line of research might consider the degree to which adults recasts provided on their own parallel AAC devices are facilitative of language acquisition over spoken recasts. Children who use AAC are an heterogeneous population, and individual differences in rates of language learning in recast-based interventions are observed in children who do not rely on AAC (e.g., Nelson, 2000). By establishing preintervention individual differences (e.g., working memory; Murray \& Goldbart, 2011) and assessing children's responses to variation in recast intervention delivery, it may be possible to customize intervention to support the broadest range of children who use AAC to their fullest capacity.

We note that where outcomes of language intervention involving AAC use are a primary measure of achievement, it can be difficult to determine whether observed progress represents core language gains or improvement in operational access to established language knowledge. Measures of change in child comprehension of language may inform this discussion. For example, clinical and research experience suggest that, while some children who use AAC may acquire vocabulary of similar size to naturally speaking children, their knowledge and use of 
morphosyntax is commonly significantly below chronological expectations and below that expected given vocabulary knowledge.

\section{Conclusion}

In this paper we have provided an overview of recasting as one central feature of adult scaffolding of child language acquisition. Drawing on literature in first language acquisition, second language learning, and communication disabilities, the paper has described types of recast design, the theoretical underpinnings of recasts as language facilitators and their clinical applications. Significant questions that remain to be answered in the AAC field concern the extent to which children who rely on AAC require feedback on errors to make progress in their ability to learn language through AAC, what types of feedback are most effective, and what is the role of child repair in language learning involving AAC. 


\section{End Notes}

${ }^{1}$ The iPad is a product of Apple Computers Inc., Cupertino, CA. www.apple.com 


\section{References}

Abbeduto, L., \& Boudreau, D. (2004). Theoretical influences on research on language development and intervention in individuals with mental retardation. Mental Retardation and Developmental Disabilities Research Reviews, 10, 184-192. doi:10.1002/mrdd.20032

Al-Surmi, M. (2012). Learners' noticing of recasts of morpho-syntactic errors: Recast types and delayed recognition. System, 40, 226-236. doi:10.1016/j.system.2012.03.001

Ammar, A., \& Spada, N. (2006). One size fits all? Recasts, prompts and L2 learning. Studies in Second Language Acquisition, 28, 543-574. doi:10.1017/S0272263106060268

Baker, N. D., \& Nelson, K. E. (1984). Recasting and related conversational techniques for triggering syntactic advances by young children. First Language, 5, 3-21. doi:10.1177/014272378400501301

Binger, C., \& Light, J. (2008). The morphology and syntax of individuals who use AAC: research review and implications for effective practice. Augmentative and Alternative Communication, 24, 123-138. doi:10.1080/07434610701830587

Bohannon, J. N., Padgett, R. J., Nelson, K. E., \& Mark, M. (1996). Useful evidence on negative evidence. Developmental Psychology, 32, 551-555. doi:10.1037/0012-1649.32.3.551

Brown, P. (1998). Conversational structure and language acquisition: The role of repetition in Tzeltal. Journal of Linguistic Anthropology, 8, 197-221. doi:10.1525/jlin.1998.8.2.197

Bybee, J. (2006). Frequency of use and the organization of language. Oxford: Oxford University Press. doi:10.1093/acprof:oso/9780195301571.001.0001 
Camarata S.M., \& Nelson K. E. (2006). Conversational recast intervention with preschool and older children (pp 237-264). In: McCauley R. J, \& Fey M. E. (Eds.). Treatment of language disorders in children. Baltimore, MD: Brookes.

Camarata, S. M., \& Nelson, K. E. (1992). Treatment efficiency as a function of target selection in the remediation of child language disorders. Clinical Linguistics \& Phonetics, 6, 16778. doi:10.3109/02699209208985528

Camarata, S. M., Nelson, K. E., \& Camarata, M. N. (1994). Comparison of conversationalrecasting and imitative procedures for training grammatical structures in children with specific language impairment. Journal of Speech and Hearing Research, 37, 1414-1423. doi:10.1044/jshr.3706.1414

Chouinard, M. M., \& Clark, E. V. (2003). Adult reformulations of child errors as negative evidence. Journal of Child Language, 30, 637-69. doi:10.1017/S0305000903005701

Clark, E. V. (2014). Pragmatics in acquisition. Journal of Child Language, 41, 105-116. doi:10.1017/S0305000914000117

Clark, E., \& de Marneffe, M-C (2012). Constructing verb paradigms in French: Adult construals and emerging grammatical contrasts. Morphology, 22, 89-120. doi:10.1007/s11525-0119193-6

Clarke, M.T. (2016) Co-construction, asymmetry and multimodality in children's conversations. In Smith, M. \& Murray, J. (Eds.). The silent partner? Language learning and language use in aided communication (pp. 177-198). London: J\&R Press

Clarke, M.T., \& Wilkinson, R. (2007). Interaction between children with cerebral palsy and their peers. 1: Organizing and understanding VOCA use. Augmentative and Alternative Communication, 23, 336-348. doi:10.1080/07434610701390350 
Eisenberg, S. L. (2013). Grammar intervention. Topics in Language Disorders, 33, 165-178. doi:10.1097/TLD.0b013e31828ef28e

Ellis, R., \& Sheen, Y. (2006). Reexamining the role of recasts in second language acquisition. Studies in Second Language Acquisition, 28, 575-600. doi:10.1017/S027226310606027X

Farrar, M. J. (1990). Discourse and the acquisition of grammatical morphemes. Journal of child language, 17, 607-624. doi:10.1017/S0305000900010904

Goo, J., \& Mackey, A. (2013). The case against the case against recasts. Studies in Second Language Acquisition, 35, 127-165. doi:10.1017/S0272263112000708

Haley, K. L., Camarata, S. M., \& Nelson, K. E. (1994). Social valence in children with specific language impairment during imitation-based and conversation-based language intervention. Journal of Speech and Hearing Research, 37, 378-388. doi:10.1044/jshr.3702.378

Heimann, M., Nelson, K., Tjus, T., \& Gillberg, C. (1995). Increasing reading and communication-skills in children with autism through an interactive multimedia computer-program. Journal of Autism and Developmental Disorders, 25, 459-480. doi:10.1007/BF02178294.

Kirchner, D. (1988). Using verbal scaffolding to facilitate conversational participation and language acquisition in children with pervasive developmental disorders. Communication Disorders Quarterly, 14, 81-98. doi:10.1177/152574018801400106

Küntay, A., \& Slobin, D. I. (2002). Putting interaction back into child language: Examples from Turkish. Psychology of Language and Communication, 6, 5-14.

Lyster, R. (1998). Recasts, repetition, and ambiguity in L2 classroom discourse. Studies in Second Language Acquisition, 20, 51-81. doi:10.1177/1362168815584454 
Lyster, R., \& Saito, K. (2010). Oral feedback in the classroom SLA. Studies in Second Language Acquisition, 32, 265-302. doi:10.1017/S0272263109990520.

Mackey, Alison and Goo, J. (2007) Interaction research in SLA: A meta-analysis and research synthesis. In: A. Mackey (Ed.) Conversational interaction in second language acquisition. (pp. 407-453). Oxford: Oxford University Press.

Miller, P. C., \& Pan, W. (2012). Recasts in the L2 classroom: A meta-analytic review. International Journal of Educational Research, 56, 48-59. doi:10.1016/j.ijer.2012.07.002

Morgenstern, A., Leroy-Collombel, S., \& Caët, S (2013) Self- and other-repairs in child-adult interaction at the intersection of pragmatic abilities and language acquisition. Journal of Pragmatics, 56, 151-167. doi: 10.1016/j.pragma.2012.06.017.

Murray, J., \& Goldbart, J. (2011). Emergence of working memory in children using aided communication. Journal of Assistive Technologies, 5, 214-232. doi:10.1108/17549451111190623.

Nelson, K. E. (1977). Facilitating children's syntax acquisition. Developmental Psychology, 13, 101-107. doi:10.1037//0012-1649.13.2.101.

Nelson, K. E. (1987). Some observations from the perspective of the rare event cognitive comparison theory of language acquisition. In K. E. Nelson (Ed.), Children's language (pp. 289-331). Hillsdale, NJ: Erlbaum.

Nelson, K. E. (2000). Methods for stimulating and measuring lexical and syntactic advances: Why Fiffins and lobsters can tag along with other recast friends. In L. Menn \& N. B. Ratner (Eds.), Methods for studying language production (pp. 115-148). Hillsdale, NJ: Erlbaum. 
Nelson, K. E., Camarata, S. M., \& Camarata, M. (1996). Effects of imitative and conversational recasting treatment on the acquisition of grammar in children with specific language impairment and younger language normal children. Journal of Speech, Language, and Hearing Research, 39, 850-859. doi:10.1044/jshr.3904.850

Nelson, K. E., \& Welsh, J. A. (1998). Progress in multiple language domains by deaf children and hearing children: Discussions with a rare event transactional model. In R. Paul (Ed.), The Speech/Language connection (pp. 179-225). Baltimore: Brookes.

Nicholas, H., Lightbown, P. M., \& Spada, N. (2001). Recasts as feedback to language learners. Language Learning, 51, 719-758. doi:10.1111/0023-8333.00172.

Oliver, R., \& Mackey, A. (2003). Interactional context and feedback in child ESL classrooms. The Modern Language Journal, 87, 519-533. doi:10.1111/1540-4781.00205.

Richards, K., \& Seedhouse, P. (Eds) (2016) Applying conversation analysis. New York: Palgrave Macmillan

Romski, M., Sevcik, R. A, Adamson, L. B., Cheslock, M., Smith, A., Barker, R. M., \& Bakeman, R. (2010). Randomized comparison of augmented and nonaugmented language interventions for toddlers with developmental delays and their parents. Journal of Speech, Language, and Hearing Research, 53, 350-364. doi:10.1044/1092-4388(2009/08-0156)

Ruston, H. P., \& Schwanenflugel, P. J. (2010). Effects of a conversation intervention on the expressive vocabulary development of prekindergarten children. Language, Speech, and Hearing Services in Schools, 41, 303-313. doi:10.1044/0161-1461(2009/08-0100)

Saxton, M. (1997). The contrast theory of negative input. Journal of child language, 24, 139161. doi:10.1017/s030500099600298x 
Saxton, M. (2005). "Recast” in a new light: Insights for practice from typical language studies. Child Language Teaching and Therapy, 21, 23-38. doi:10.1191/0265659005ct279oa

Schegloff, E., Jefferson, G., \& Sacks, H. (1977). The preference for self-correction in the organization of repair in conversation. Language, 53, 361-382. doi:10.2307/413107

Scherer, N. J., \& Olswang, L. B. (1989). Using structured discourse as a language intervention technique with autistic children. Journal of Speech and Hearing Disorders, 54, 383-394. doi:10.1044/jshd.5403.383

Scollon, R. (1976). Conversations with a one year old: A case study of the developmental foundation of syntax. Honolulu: University Press of Hawaii.

Sheen, Y. (2006). Exploring the relationship between characteristics of recasts and learner uptake. Language Teaching Research, 4, 361-392. doi:10.1191/13621688061r203oa

Smith, M. M. (2015). Language development of individuals who require aided communication: reflections on state of the science and future research directions. Augmentative and Alternative Communication, 31, 215-233. doi:10.3109/07434618.2015.1062553

Solomon-Rice, P., \& Soto, G. (2011). Co-construction as a facilitative factor in supporting the personal narratives of children who use augmentative and alternative communication. Communication Disorders Quarterly, 32, 70-82. doi:10.1177/1525740109354776

Soto, G., \& Clarke, M. T. (in press). Effects of a conversation-based intervention on the linguistic skills of children with motor speech disorders who use augmentative and alternative communication. Available from authors on request

Stiegler, L. N., \& Hoffman, P. R. (2001). Discourse-based intervention for word finding in children. Journal of Communication Disorders, 34, 277-303. doi:10.1016/S00219924(01)00051-X 
Sutton, A., Soto, G., \& Blockberger, S. (2002). Grammatical issues in graphic symbol communication. Augmentative and Alternative Communication, 18, 192-204. doi:10.1080/07434610212331281271

Tjus, T., Heimann, M., \& Nelson, K. E. (1998). Gains in literacy through the use of a specially developed multimedia computer strategy: Positive findings from thirteen children with autism. Autism, 2, 139-156. doi:10.1177/1362361398022003 


\section{Extract 1}

$01 \mathrm{~T} \quad$ So tell me about this picture what happen that day? what's happening?

02 C "I to go my house cousin Alex Aby"

$03 \mathrm{~T}$ Ok that's a little confusing so were you at your house?

$\rightarrow \quad 04 \quad$ You went to your cousin house and your cousins are Alex and Aby?

$\rightarrow \quad 05 \quad \mathrm{C} \quad(($ nods $))$

\section{Extract 2}

\begin{tabular}{|c|c|c|c|}
\hline & 01 & $\mathrm{M}$ & "Boy" \\
\hline & 02 & $\mathrm{~T}$ & Boy what? \\
\hline & 03 & M & "Reading a book" \\
\hline & 04 & $\mathrm{~T}$ & Boy reading a book? \\
\hline & 05 & M & $(($ nods $))$ \\
\hline
\end{tabular}




\section{Extract 3}

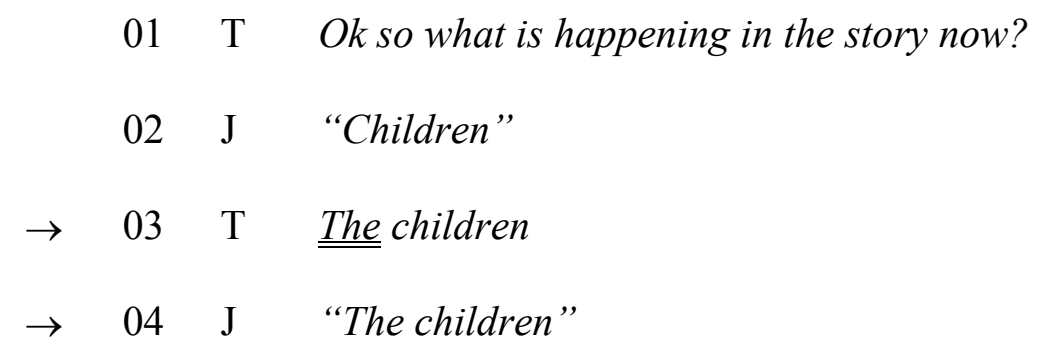

\section{Extract 4}

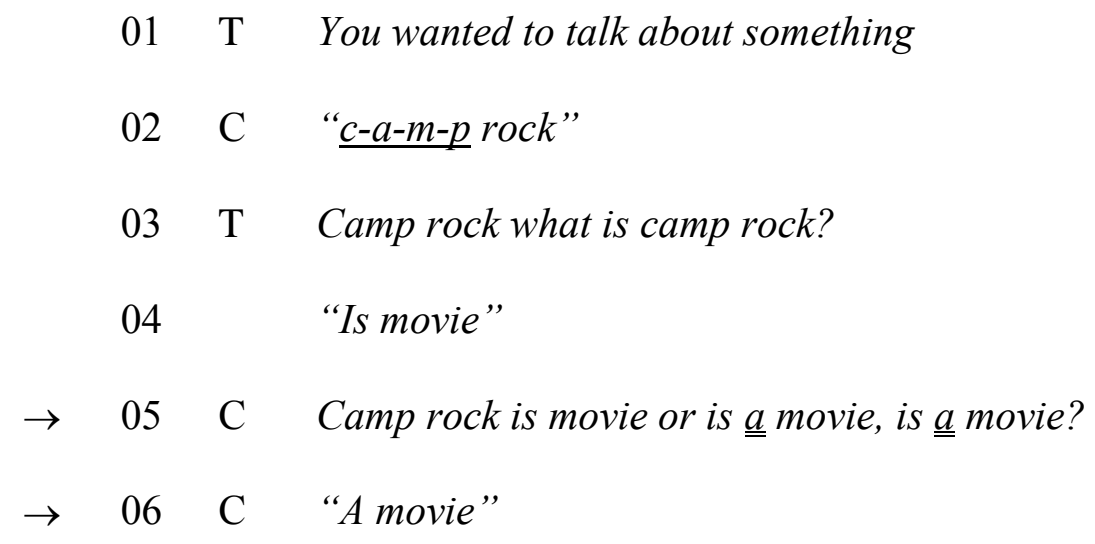




\section{Extract 5}

01 N "I want playground"

$\rightarrow \quad 02 \mathrm{~T} \quad$ You want to go to the playground? this is a great sentence.

$\rightarrow \quad 03 \mathrm{~N} \quad$ "I want to go playground"

\section{Extract 6}

$01 \mathrm{~T} \quad$ How old were you here?

02 C " 6 "

$\rightarrow \quad 03 \quad \mathrm{~T} \quad$ You were 6 years old so that was 3 years ago

$\rightarrow \quad 04 \quad \mathrm{C} \quad$ "6 years old" 


\section{Extract 7}

$\begin{array}{cccl}\rightarrow & 01 & \mathrm{~N} & \text { "Sled" } \\ & 02 & \mathrm{~T} & \text { Is that something you did? } \\ & 03 & \mathrm{~N} & ((\text { nods })) \\ \rightarrow & 04 & \mathrm{~T} & \text { You went on the sled? } \\ \rightarrow & 05 & \mathrm{~N} & (\text { (nods) })\end{array}$

\section{Extract 8}

$\begin{array}{llll}\rightarrow & 01 & \text { M } & \text { "Boy" } \\ & 02 & \text { T } & \text { Boy? } \\ & 03 & \text { M } & ((\text { nods })) \\ \rightarrow & 04 & \text { T } & \text { The boy is waving? } \\ \rightarrow & 05 & \text { M } & \text { "Yeah" }\end{array}$

